\title{
Centrais de pequenos supermercados no estado de São Paulo: evolução da coordenação e coesão relacional
}

\author{
Luciano Mitidieri Bento Garciaa*, Luiz Fernando de Oriani e Paulillo ${ }^{\text {b }}$ \\ a*Igarcia@dep.ufscar.br, UFSCar, Brasil \\ bdlfp@power.ufscar.br, UFSCar, Brasil
}

\begin{abstract}
Resumo
Este trabalho visa mostrar e analisar um grupo de redes de pequenos supermercadistas no interior do estado de S. Paulo operando por meio de relações cooperativas sob a forma de centrais de negócios. Dentro de uma abordagem qualitativa de pesquisa e utilizando os aportes teóricos do neoinstitucionalismo e teoria de redes, o trabalho foi baseado em entrevistas semiestruturadas com os representantes de quatro centrais. Foi seguido um roteiro composto por itens relacionados à história de formação da central, motivações principais para entrada na rede, fases de desenvolvimento, detalhes operacionais e algumas indicações sobre os mecanismos de coordenação e as características das relações mais relevantes. Constata-se, no caso dos mecanismos de coordenação, uma importante convivência entre mecanismos formais e informais de coordenação. Quanto às relações entre os membros, de modo geral, elas se revelaram coesas. Constata-se também uma alta percepção de eficácia nas centrais estudadas.
\end{abstract}

Palavras-chave

Supermercados. Redes. Coordenação. Coesão. Eficácia.

\section{Introdução}

0 setor supermercadista é marcado pela sua importância em termos de geração de empregos e participação na geração da riqueza econômica de uma nação. Segundo dados divulgados pela Abras - Associação Brasileira de Supermercados, o setor supermercadista empregava em 2009 mais de 900 mil pessoas no Brasil, detendo uma participação de 5\% do produto interno bruto. Além disso, o setor supermercadista desempenha um papel estratégico crucial como canal de distribuição de bens produzidos na indústria e agricultura. Especialmente com relação aos gêneros alimentícios, o setor supermercadista, como participante do sistema agroalimentar, tem adquirido nos últimos anos posição de destaque.

Não só no pequeno varejo supermercadista mas também em outras modalidades de pequeno varejo tais como papelarias, lojas de material de construção e farmácias o associativismo tem estado presente como forma de superar os desafios competitivos impostos pelo avanço da concentração de mercado nesses setores. No caso dos supermercados, o associativismo se manifesta através da reunião e estruturação de pequenos negócios independentes em torno redes interorganizacionais horizontais denominadas centrais de compras ou centrais de negócsio. 0 objetivo básico e inicial dessas centrais é o de, por meio de compras conjuntas realizadas junto aos fornecedores da indústria, da agricultura ou atacadistas, fazer com que os pequenos possam reproduzir ou pelo menos se aproximar do mesmo poder de barganha dos grandes grupos.

0 presente artigo tem seu foco de estudo em um grupo de centrais de negócios de pequenos estabelecimentos supermercadistas do interior do estado de S. Paulo. Essas centrais foram analisadas enquanto redes de relações econômicas e sociais.

Este artigo se divide em seis itens, sendo que o primeiro se constitui nesta introdução. 0 item dois apresenta uma breve revisão da abordagem neoinstitucional de redes, arcabouço teórico utilizado neste trabalho. 0 item três apresenta algumas considerações sobre as centrais de negócios de 
pequenos estabelecimentos supermercadistas no Brasil e suas principais características. Considerações metodológicas são apresentadas no item quatro, onde também são expostas as variáveis utilizadas para a análise das centrais enfocadas. No item cinco apresentam-se os quatro casos de centrais de negócios analisados neste artigo com os relatos obtidos em cada central. Finalmente, no item seis é feita uma análise desses relatos e, no item sete, as conclusões finais são apresentadas.

\section{Neoinstitucionalismo sociológico (NIS) e redes de empresas - aspectos teóricos}

0 NIS, em linhas gerais, se contrapõe ao pensamento racionalista, estabelecendo seu foco em aspectos culturais e cognitivos, bem como nas relações sociais individuais ou grupais. Segundo Hall e Taylor (1996), o NIS surge com um enfoque de natureza cognitiva, numa forte relação com a teoria das organizações, postulando que as normas e procedimentos não surgem como uma resposta eficiente da sociedade para a execução de tarefas, mas sim como práticas culturais (cerimônias e mitos) que se assemelham, constituindo-se em um processo denominado isomorfismo, ou seja, a tendência de as organizações tornarem-se semelhantes ao longo do tempo.

DiMaggio e Powell (1983) definem três formas de isomorfismo: coercitivo, normativo e mimético. 0 isomorfismo mimético se define como a adaptação de procedimentos e estruturas de uma organização, percebidos e disseminados como sucessos, por outra, com a finalidade de reduzir a incerteza. 0 isomorfismo coercitivo é gerado no âmbito de regulamentações exógenas, como leis previdenciárias e trabalhistas, ou ainda devido à existência de um ator com poder de regulação, ou ainda devido às pressões formais ou informais, emanadas de uma organização "chave" para as demais, ou mesmo pela própria pressão cultural da sociedade. 0 isomorfismo normativo se refere mais aos setores onde é bem definida a profissionalização de uma categoria ou de acordo com estruturas normativas existentes no ambiente institucional; nesta modalidade, uma determinada categoria profissional define suas práticas de trabalho e essas práticas são disseminadas por um processo de educação formal.

Como um produto da evolução capitalista contemporânea, a incidência de formas mais sofisticadas de cooperação e relacionamento entre empresas chama a atenção de pesquisadores para a importância do seu estudo e de suas implicações em termos de desempenho e competitividade. Estrutura-se assim, especialmente a partir dos anos
1990, uma abordagem baseada no conceito de rede de empresas voltada para fenômenos caracterizados por relacionamentos cooperativos indutores de interdependência entre os agentes, que gera a necessidade de formas de coordenação coletiva das suas atividades.

A operação através de redes de cooperação desenvolve-se com seus integrantes atuando de forma independente mas coordenada (e, por vezes, temporária), explorando complementaridades mútuas e compartilhando informações, riscos, recursos e produção. lsso se apresenta com grande relevância quando se trata da sobrevivência de pequenas e médias empresas pois, no entendimento de Casarotto e Pires (2001), esse tipo de empresa enfrenta uma série de obstáculos à sua competitividade e sobrevivência, frutos da crescente complexidade de mercados cada vez mais concentrados.

Considera-se que, fundamentalmente, o processo de estruturação e evolução das organizações em geral, e em especial das redes, envolve não apenas fatores econômicos tais como aumento de escala de compras para redução de custo médio de aquisição, melhoria de eficiência econômica ou mesmo redução de custos de transação. Ainda que os fatores econômicos não possam ser descartados, existem também componentes sociais e institucionais tais como a busca da legitimidade, a importância da homogeneidade do grupo, os mecanismos de coordenação em redes, a intensidade das relações e a questão da confiança e da reciprocidade para a manutenção da rede.

Por outro lado, a construção e gestão de qualquer arranjo cooperativo apresenta uma série de desafios e obstáculos. 0 compartilhamento de conhecimentos, de informações e experiências necessita, portanto, da construção cuidadosa da integração bem como da superação da desconfiança.

Um aspecto da ação cooperativa na forma redes de empresas é a existência de mecanismos de coordenação formais e informais. Os mecanismos de coordenação se apresentam como um aspecto importante do funcionamento das redes, sendo que, especialmente nos casos analisados, há uma nítida combinação entre formalidade e informalidade. Especialmente neste trabalho encontram-se tanto aqueles mecanismos de coordenação mais sintonizados com o controle e formalismo, tais como o estatuto da rede, atas de reuniões e regras de controle, como também mecanismos informais, baseados em confiança e reciprocidade.

Teoricamente, dentre os mecanismos de coordenação definidos por Grandori e Soda (1995) e apresentados também por Sacomano Neto e Truzzi (2005) estão, em resumo, comunicação, controle social, 
regras, planejamento, incentivo, seleção de parceiros, sistemas de informação e suporte público/externo - o mecanismo de seleção de parceiros revelou-se de grande importância para a manutenção de rede do tipo central de negócios e por esse motivo recebeu atenção especial no trabalho de campo. Por outro lado, dada a presença de mecanismos informais de coordenação, baseados em reciprocidade e confiança, o aspecto relacional em termos de intensidade de relações entre integrantes da rede também mereceu destaque especial. A intensidade das relações é importante para que a coordenação informal baseada em reciprocidade e confiança se desenvolva adequadamente. Alguns aspectos de coesão relacional de redes definidos, por exemplo, em Sacomano Neto e Truzzi (2005), foram então utilizados neste trabalho, tais como a existência de vínculos prévios entre os participantes de uma rede, a intensidade emocional das relações verificada através de relações sociais e de amizade entre os participantes da rede e ações de reciprocidade entre membros da rede.

\section{As centrais de negócios}

Teoricamente, as centrais de negócios podem se enquadrar no conceito de rede interorganizacional horizontal de empresas, ou seja, tem-se um agrupamento cooperativo de empresas "em que as relações se dão entre empresas que produzem e oferecem produtos similares, pertencentes ao mesmo setor, isto é, entre uma empresa e seus próprios concorrentes ou ramo de atuação" (MARTINELLI et al., 2003, p. 6). As centrais de negócios podem também ser consideradas alianças estratégicas, onde se tem compartilhamento de recursos e competências e redução de custos e, neste caso, as centrais seriam definidas como uma aliança do tipo comercial (OLIVEIRA LIMA et al., 2006).

As funções principais, exercidas em uma central de negócios, são resumidas em lopes et al. (2004) como compras, promoção e divulgação conjunta, padronização de lojas, treinamento de funcionários e desenvolvimento de marca própria. Wilder (2003) chama as relações de uma rede de negócios de "simbioses", nelas é gerado um valor para todos os participantes sob a forma de redução no número de transações, reduzindo, portanto, os custos de transação. Cria-se uma estrutura híbrida de governança (MENARD, 2004) que combina hierarquia e mercado, na medida em que as firmas participantes permanecem independentes mas combinam algumas atividades, como compras, auferindo com isso economias de escala.

0 tipo de supermercadista que normalmente adere às centrais de compras é aquele que opera lojas do tipo supermercado compacto. Em termos de localização são, em sua maioria, supermercados de vizinhança. Campos (2003) aponta que as chamadas lojas de vizinhança, com até quatro check-outs e com uma área média de $250 \mathrm{~m}^{2}$, ocupam um lugar de destaque nas preferências de consumo da população da classe $\mathrm{C}$, cujas compras são feitas nas proximidades de seu domicílio e em menores quantidades, entre outras razões por não dispor de condução própria. A atratividade das lojas de vizinhança já vinha chamando a atenção dos grandes grupos, que começam a divulgar planos de abertura de lojas de menor porte para explorar exatamente esse nicho. Assim, o fortalecimento do varejo independente torna-se uma necessidade para os pequenos proprietários e, nesse contexto, as centrais de negócios já apareciam com uma alternativa a ser explorada pelos pequenos estabelecimentos.

As centrais de negócios, como já observado, inicialmente tentam suprir as deficiências de escala e de poder de barganha típicas do pequeno varejo mediante a ação conjunta de compras junto aos fornecedores. A compra conjunta, pelo seu maior valor em comparação com as compras de cada associado tomado separadamente, dá ao grupo melhores possibilidades de negociação em termos de preço e prazo, o que pode ser repassado pelos pequenos supermercadistas ao seu preço final, gerando, consequentemente, melhores condições competitivas frente aos grandes grupos. Segundo Saab e Gimenez (2000), o próprio acesso a determinados fornecedores, que seria impossível para o pequeno supermercado individualmente, passa a ser possível a partir da cooperação entre eles.

Os números apontam, segundo a pesquisa da Associação Brasileira de Supermercados (Abras), para a continuidade do crescimento do setor de centrais de negócios, com 3.500 lojas e um faturamento anual próximo dos $\mathrm{R} \$ 20$ bilhões. Uma das explicações para esse tipo de evolução acima da média em relação ao varejo supermercadista como um todo se encontra no fato de que a maior parte dos supermercadistas participantes de centrais tem como público principal as classes C, D e E. Essas classes têm seu domicílio localizado nas periferias das cidades e são as principais beneficiárias do ciclo de aumento de emprego e renda iniciado em meados de 2004 e intensificado a partir de meados de 2009.

De acordo com a Tabela 1, adaptado de material editado pelo Comitê da Associação Paulista de Supermercados (Apas) de Centrais de Negócios relativo ao período 2009/2010 (ASSOCIAÇÃO..., 2009), tem-se um conjunto de 332 lojas, com 229,4 mil metros quadrados de área total de vendas, 12.600 funcionários e presença em 153 cidades do estado. Nota-se que as atuais 18 centrais filiadas à Apas são 
Tabela 1. Dados sobre as centrais de negócios no estado de São Paulo.

\begin{tabular}{|c|c|c|c|c|c|c|c|c|c|}
\hline Rede & Fundação & Lojas & Área $\left(\mathrm{m}^{2}\right)$ & Func. & Caixas & Cidades & M $^{2} /$ Loja* & Func./Loja** & Caixas/Loja*** \\
\hline 1 & 2000 & 32 & 8.650 & 547 & 88 & 7 & 270 & 17 & 3 \\
\hline 2 & 1995 & 14 & 10.500 & 700 & 90 & 7 & 750 & 50 & 6 \\
\hline 3 & 2000 & 14 & 13.000 & 531 & 54 & 8 & 929 & 38 & 4 \\
\hline 4 & 1999 & 14 & 6.200 & 210 & 35 & 3 & 443 & 15 & 3 \\
\hline 5 & 1999 & 11 & 6.000 & 382 & 58 & 6 & 545 & 35 & 5 \\
\hline 6 & 2000 & 23 & 9.340 & 471 & 91 & 5 & 406 & 20 & 4 \\
\hline 7 & 1999 & 31 & 25.305 & 1.553 & 226 & 7 & 816 & 50 & 7 \\
\hline 8 & 1996 & 11 & 6.760 & 148 & 36 & 3 & 615 & 13 & 3 \\
\hline 9 & 2006 & 5 & 1.700 & 80 & 22 & 3 & 340 & 16 & 4 \\
\hline 10 & 1996 & 20 & 17.500 & 895 & 167 & 16 & 875 & 45 & 8 \\
\hline 11 & 2004 & 13 & 1.200 & 200 & 25 & 8 & 92 & 15 & 2 \\
\hline 12 & 2005 & 44 & 59.572 & 3.019 & 450 & 26 & 1.354 & 69 & 10 \\
\hline 13 & 2001 & 15 & 10.000 & 520 & 100 & 4 & 667 & 35 & 7 \\
\hline 14 & 2000 & 21 & 13.500 & 800 & 130 & 18 & 643 & 38 & 6 \\
\hline 15 & 2006 & 8 & 3.150 & 125 & 28 & 2 & 394 & 16 & 4 \\
\hline 16 & 2002 & 19 & 11.000 & 650 & 111 & 11 & 579 & 34 & 6 \\
\hline 17 & 2008 & 12 & 12.600 & 900 & 122 & 9 & 1.050 & 75 & 10 \\
\hline 18 & 2008 & 25 & 13.500 & 870 & 137 & 10 & 540 & 35 & 5 \\
\hline Total & & 332 & 229.477 & 12.601 & 1.970 & 153 & & & 510 \\
\hline Média ajust. & & & & & & & 33 & 5 \\
\hline
\end{tabular}

${ }^{*} \mathrm{M}^{2} /$ Loja: área total dividida pelo total de lojas; ${ }^{* *}$ Fun./Loja: número total de funcionários dividido pelo número total de lojas; ${ }^{* * *}$ Caixas/Loja: número total de caixas dividido pelo total de lojas. Obs.: no total de cidades, o somatório 153 pode estar superavaliado, pois existe sobreposição de centrais, isto é, existem cidades que sediam de mais de uma central. Fonte: adaptado de documento do Comitê de Centrais de Negócios da Apas 2009 (ASSOClAÇÃ0..., 2009).

arranjos relativamente recentes. A mais antiga foi fundada em 1995, pouco mais de 15 anos, portanto. Mas a maioria possui em torno de 10 anos de vida, no máximo (algumas têm menos de três anos de fundação), o que, em termos organizacionais, não pode ser considerado um tempo de vida longo. Esse fato leva à constatação de que as centrais ainda estão, de modo geral, em seus estágios iniciais de evolução. Outra informação interessante que emerge dessa tabela é que o porte médio das lojas não pode ser considerado tão pequeno. São lojas com área média de vendas (média ajustada) superando os $600 \mathrm{~m}^{2}$, 6 check-outs e mais de 30 funcionários por loja. Conforme a classificação da Abras, esse porte, em que pese ainda ser classificado como pequeno de acordo com a referida classificação (supermercado compacto), já se aproxima do limite superior da classificação da Abras em termos de área de vendas (de 300 a $700 \mathrm{~m}^{2}$ ) e número de caixas (de 2 a 6 caixas). Esse dado pode indicar uma movimentação dos estabelecimentos menores em direção a um nível superior de porte (supermercado convencional).

\section{Metodologia}

A pesquisa que ampara este artigo foi desenvolvida por meio de quatro estudos de caso em quatro centrais de negócios sediadas em cidades do interior do estado de São Paulo. Segundo Yin (2001), o estudo de caso emprega uma série de técnicas entre as quais se destacam a observação direta e as entrevistas. No caso deste trabalho, além de uma análise documental, foram realizadas entrevistas. Sendo o estudo de caso e análise comparativa as formas principais de investigação, foram executadas as etapas a seguir:

- Análise do caso em si: para consolidar as anotações retiradas de diversas fontes;

- Comparação entre os casos;

- Análise de dados coletados;

- Conclusões finais e adaptações após a investigação empírica.

Os dados foram coletados através de entrevistas semiestruturadas junto aos representantes de cada central de negócios, seguindo um roteiro composto por itens relacionados ao histórico e evolução das centrais, motivações, fases pelas quais passaram, percepção de eficácia, efetividade da coordenação e coesão relacional. Complementou-se o estudo com a análise de conteúdo dos relatos colhidos.

Neste trabalho é apresentado, portanto um estudo comparativo com quatro casos: o primeiro caso, da rede $X$, localizada na região nordeste do estado, foi colhido mediante entrevistas com três dos associados fundadores. No segundo caso, é apresentada a rede $\mathrm{Y}$, localizada na região central do estado, no extremo oposto da rede $X$. Para essa central foi colhido o depoimento de um representante da rede: o supermercadista que presidia a central naquele momento. 0 terceiro caso apresenta a rede 
$\mathrm{Z}$, localizada em região próxima da rede $\mathrm{Y}$, mais ao sul, concretizado através de relato colhido junto ao comprador e administrador geral da rede. No quarto caso, finalmente, tem-se a rede $\mathrm{W}$, localizada na mesma região da rede $\mathrm{X}$ e com ela concorrendo em várias cidades, inclusive na cidade sede. Nesse último caso, o relato foi obtido do supermercadista presidente da rede naquele momento, tal como na rede $\mathrm{Y}$. Por fim, tem-se a rede $\mathrm{W}$, localizada na mesma região da rede $X$.

Após a transcrição das entrevistas gravadas, foi feita uma análise do conteúdo dos relatos colhidos junto aos representantes dessas redes. Essa análise priorizou as origens da rede, seu desenvolvimento recente, estrutura atual e percepções de seus representantes quanto a alguns aspectos de coordenação, especialmente o processo de seleção de novos parceiros, além de aspectos relacionais em termos de vínculos prévios e da intensidade emocional dos relacionamentos. Foram relatos com um roteiro prévio, mas que nem sempre foi seguido à risca tendo em vista o caráter dinâmico das conversas. Optou-se por deixar os entrevistados à vontade, contando suas histórias, com um mínimo de intervenção, para realmente captar o máximo de informações de forma natural e espontânea. Isso feito, procedeu-se a uma análise desses relatos tendo em vista seus pontos comuns e divergências.

\section{Casos estudados}

Neste item tem-se a essência do que foi colhido nos relatos de cada uma das centrais pesquisadas. Seguem-se os relatos das entrevistas.

\section{1. $O$ caso da rede $X$}

Para este relato foram feitas entrevistas com três fundadores, doravante supermercadistas X1, X2, e X3. $A$ rede $X$ tem sua origem quando três supermercadistas da região com fortes laços familiares e de amizade participaram de um evento da Apas em 1999 sobre o tema do cooperativismo e resolveram em outubro de 2000 iniciar um processo de compra conjunta de mercadorias visando: "... a nossa própria sobrevivência, porque do jeito que a gente estava, a gente ia morrer" (supermercadista X1). Foi feito o convite para um quarto supermercadista (o supermercadista X4), também conhecido e que também participara do evento da Apas. Em caráter experimental, passaram a comprar conjuntamente apenas um produto de cada vez e em baixa quantidade. 0 intuito era ir gradativamente expandindo e, caso o resultado fosse bom, estender as compras, consolidando a central.
Nessa etapa, as atividades conjuntas se deram em caráter informal, baseadas na confiança, com as encomendas realizadas em nome de um deles e depois repassadas para os demais, sem controles formais. Ao sentirem que o negócio estava: "fluindo" (supermercadista X1), decidiram expandir as atividades, ainda em caráter informal. Cada um dos quatro fundadores trouxe um amigo com quem tinha vínculos prévios e, assim, o grupo totalizou oito integrantes. Numa segunda fase, cada amigo convidado trouxe outro amigo, chegando-se a 16 associados.

Em outubro de 2000, após um ano de funcionamento informal, os 16 integrantes decidiram pela formalização, com a criação de um regulamento e um estatuto. Durante todo esse período inicial foram feitas também visitas a outras duas redes já existentes em busca de modelos de estatuto, processos etc.

De 2000 a 2005, o grupo ainda funcionou como uma associação sem fins lucrativos, composta por pessoas jurídicas, numa forma de contornar a questão da bitributação. A mercadoria: “... por ser sem fins lucrativos" (supermercadista X2), não sofria tributação na entrada e na saída para os estabelecimentos. Para o custeio desta estrutura: “... era cobrada uma mensalidade fixa de cada associado" (supermercadista X2). Em 2004, o governo decretou uma modificação tributária. O PIS e Cofins que incidiam sobre o faturamento passaram a incidir sobre o valor agregado (“... isso abriu uma porta para nós" - supermercadista X2). Foi feito um cálculo de quanto seria agregado de valor à mercadoria para: “... custear e rede como um todo" (supermercadista $\mathrm{X} 2$ ). As mercadorias seriam adquiridas e revendidas por uma empresa de atacado aos supermercadistas associados do grupo e os tributos incidiriam sobre um valor agregado pelo atacado e estipulado pelos supermercadistas de modo a cobrir os custos da central.

Assim, a partir de 2005 até os dias de hoje, instituiu-se um modelo de organização de central de negócios mais profissionalizado com a criação de um atacado, com sua própria operação, fornecendo aos supermercadistas, denominada pelo supermercadista X2 de: “... a logística da rede".

Em termos de seleção de parceiros, a partir da formalização iniciada numa primeira etapa, houve a criação de um regulamento interno onde se estabeleceram critérios e regras mais estruturadas. De 2000 a 2005, os critérios eram: distância mínima de $2 \mathrm{~km}$ entre o novo entrante e qualquer supermercadista da central; concordância unânime de todos os associados; levantamento comercial junto a fornecedores sobre a idoneidade do postulante; exigência de um mínimo de 10 anos em atividade comercial. Após 2005, quando se modificou o modelo de atuação, foram instituídas modificações 
na seleção de parceiros e na coordenação de modo geral, com critérios mais rígidos e próprios de empresas formalizadas: entrada permitida com dois terços de votos dos associados; distância mínima de $3 \mathrm{~km}$ (podendo ser menor desde que o supermercadista envolvido concorde com a maior proximidade), três anos comprovados de atividade no comércio; e, por fim, a penhora de um imóvel de propriedade do entrante em favor da central como garantia, de modo que $80 \%$ do valor desse imóvel represente o valor da compra que o sócio pode efetuar pela central, "um valor que ele vai poder deixar em aberto com a rede, que é a carteira dele dentro da rede" (supermercadista X2).

$\mathrm{Na}$ época das entrevistas (entre outubro e novembro de 2010), a rede $X$ contava com 24 supermercadistas e 32 lojas, distribuídas em sete cidades da região. Com visual e serviços padronizados, as lojas da rede X empregavam 547 funcionários, somando um total de 8.650 metros quadrados de área de vendas e operando com um total de 88 check-outs. Além da compra conjunta, compartilham ações de marketing (distribuição aos clientes de 720 mil folhetos de ofertas por mês), contabilidade e logística (armazenagem e controle de estoques). De posse desses números e em comparação com as demais centrais do estado filiadas à Apas, a rede $\mathrm{X}$ pode ser considerada uma central de grande porte.

Foram feitas referências a vários mecanismos de coordenação e controle sobre os sócios. No caso, por exemplo, das decisões conjuntas, uma modificação importante a partir da segunda fase de vida da central iniciada em 2005 foi a instituição da igualdade de voto entre os associados. Antes dessa fase havia um peso de voto ligado ao porte de cada associado em termos de quantidade de lojas. Em termos de controle, instituiu-se o bloqueio do crédito ao associado que atrasar mais do que três dias o seu pagamento à central. A própria penhora do imóvel funcionando como um forte mecanismo de coordenação e controle.

Em termos de relacionamentos, registrou-se uma intensidade emocional forte de relacionamentos, formando um grupo de: "... amigos ou que acabaram ficando amigos porque começamos a conviver" (supermercadista $\mathrm{X} 1$ ). Uma prova dessa coesão se evidencia na ocorrência de reuniões sociais mensais (normalmente churrascos, jantares etc.) entre os integrantes do grupo e famíliares, gerando um estreitamento da interação entre os supermercadistas.

Um mecanismo informal interessante de compensação de excesso e falta de mercadorias encontrado na rede $X$ (e em operação nas outras redes, como se verá a seguir) é uma evidência clara de relações de reciprocidade e confiança. Um integrante, por exemplo, que esteja com falta de mercadoria, ao invés de adquiri-la no fornecedor ou em outro estabelecimento, pagando mais caro, pode emprestar essa mercadoria com quem a tenha sobrando, devolvendo-a numa próxima oportunidade, ou pagando o valor equivalente em dinheiro. Da mesma forma, caso alguma mercadoria esteja sem saída, ela pode ser encaminhada para outro estabelecimento onde sua demanda esteja mais forte. 0 aspecto interessante é que esse tipo de prática, apesar de previsto no estatuto da rede, se dá no dia a dia de maneira não formalizada, sem nenhum tipo de papel ou registro (a não ser os controles internos de entrada e saída de mercadorias, feitos por cada supermercadista no âmbito de sua loja), sendo totalmente realizado em termos de confiança, sem nenhum contrato que preveja sanções àqueles que não cumpram com a sua parte nesse acordo.

\section{2. $O$ caso da rede $Y$}

De acordo com o representante da rede - doravante chamado supermercadista $Y 1$, a rede $Y$ teve seu início de maneira informal em outubro de 2004, a partir de um grupo de cinco supermercadistas de cidades de porte médio localizadas na região centro-leste do estado de S. Paulo. 0 ponto de partida foi um evento do Sebrae/SP - Serviço Brasileiro de Apoio à Micro e Pequena Empresa do Estado de S. Paulo, realizado em conjunto com a Associação Comercial, Industrial e Agrícola local que, por meio do programa Empreender, idealizado pelo Sebrae, visava fomentar o associativismo e a cooperação entre pequenas empresas de diversos segmentos, dentre os quais o setor supermercadista. Durante os primeiros dois anos, um grupo inicial de 13 supermercadistas passou a realizar reuniões, fazendo algumas compras conjuntas de mercadorias de mais alto giro e que possibilitassem maior volume de compras. Assim que sentiram possuir: “... um grupo coeso" (supermercadista Y1), resolveram formalizar de vez a atividade nos moldes de uma central de negócios em maio de 2006. Contudo, dos 13 associados iniciais do grupo, restaram apenas cinco dispostos a prosseguir com a idéia.

Importante observar que, diferentemente da rede $X$, esses cinco supermercadistas fundadores da rede $Y$ não possuíam vínculos prévios relevantes a não ser algum conhecimento pelo nome ou um conhecimento superficial típico em cidades do interior, ou nem mesmo isto. Alguns deles se conheceram efetivamente no evento do Sebrae, o que ressalta a importância da ação institucional (e, nesse caso, uma ação que também não teve sua origem na Apas), além dos vínculos prévios, na formação das centrais de negócios. Representantes da rede $Y$ visitaram duas redes mais antigas e já consolidadas, uma delas a própria rede X, em busca de modelos de estatutos, 
regulamentos, operações, procedimentos etc. Também, novamente, o Sebrae participou dando apoio sob a forma de informações sobre grupos de ações conjuntas espalhados pelo estado de S. Paulo com os quais tinham relações. Assim, após essa etapa, a rede $Y$ nasce formalmente sob a forma de associação para compras conjuntas em maio de 2006, com um estatuto ou "regimento interno" como associação ainda sem fins lucrativos e não com um atacado nos moldes da rede $X$ : “... quando sentirmos firmeza” (supermercadista $Y 1$ ).

Indagado sobre as razões pelas quais alguns supermercadistas do primeiro grupo de 13 não prosseguiram, o supermercadista $Y 1$ afirmou que além de alguns não terem se conscientizado do espírito da ação cooperativa, pois “... só buscavam vantagens" (supermercadista Y1), alguns fecharam as portas devido à concorrência muito forte apresentada pela vinda de três grandes grupos para a cidade, uma deles o grupo Pão de Açúcar. Aliás, uma das razões do não fechamento dos cinco supermercadistas que prosseguiram com o projeto de ação conjunta foi, segundo seu representante, a própria constituição da central, que thes deu maiores condições de competir com os supermercados maiores recém-chegados à cidade.

Atualmente, os cinco supermercadistas da rede $Y$ possuem um total de oito lojas, somando 3.150 metros quadrados de área de vendas. Operam com 125 funcionários e 28 check-outs. Exceto por uma loja, localizada em cidade vizinha, todas as demais se localizam na cidade de origem. A associação conta ainda com um comprador contratado, dois funcionários, armazém e um caminhão com motorista e distribui $144 \mathrm{mil}$ folhetos/mês. Bem menor do que a rede $X$, além de mais jovem, a rede $Y$ pode ser considerada uma central de pequeno porte em comparação com as demais centrais do estado filiadas à Apas.

Apesar da inexistência de laços prévios na sua origem, o representante da rede $Y$ afirma serem eles hoje amigos, com intenso convívio social. Além das vantagens econômicas, a troca de experiências e informações também é considerada um benefício proporcionado pela ação conjunta: “... nós ganhamos muito em conhecimento e troca de informações" (supermercadista Y1).

Quanto ao processo de seleção de novos parceiros, apesar de informar que no momento não estariam interessados, os procedimentos assemelham-se aos da rede $\mathrm{X}$, com pesquisa junto a fornecedores sobre pontualidade no pagamento e comportamento comercial que gere: “... problemas futuros" (supermercadista Y1). Relações de reciprocidade foram constatadas, com mecanismos de compensação de mercadorias baseados em confiança, nos mesmos moldes da rede $X$.

Um último fato interessante informado nesse relato foi, em 2010, a aquisição conjunta por parte dos cinco integrantes da central, mais o comprador da central como sexto sócio, de um supermercado em cidade próxima, a primeira loja fora do município sede dos cinco fundadores. Este tipo de crescimento, através de loja própria da rede como um todo e não mediante admissão de novos parceiros, foi informado como sendo a forma pela qual a rede Y pretende crescer.

\section{3. $O$ caso da rede $Z$}

$A$ rede $Z$ atua na região central do estado. Segundo relato de seu representante, neste caso o comprador da central, a rede $Z$ teve seu início em novembro de 1999. Naquela ocasião, um grupo de 13 pequenos supermercadistas que, a exemplo da rede $X$, possuíam laços prévios de amizade ou parentesco (três irmãos participantes do grupo original) e diante do aumento da concorrência na cidade, representado pela entrada de supermercados como Covabra, Atacadão (Carrefour), Maxxi (Walmart) e Assaí (Pão de Açúcar), decidiu atuar de forma conjunta: “... percebemos que o mercado estava ficando muito competitivo, os grandes chegando cada vez mais na nossa cidade" (representante da rede $\mathrm{Z}$ ).

Após uma série de reuniões e deliberações, decidiu-se formar um grupo para compras conjuntas, inicialmente no mesmo padrão informal já relatado nas redes $\mathrm{X}$ e $\mathrm{Y}$, com compras limitadas e realizadas informalmente, o que significava fazer a transação de compra em nome de um do grupo, o qual depois se encarregava de repassar a mercadoria aos demais, toda uma transação realizada na base da confiança: “... faturava em nome de um, depois faturava em nome de outro, na confiança” (representante da rede Z). Durante aproximadamente um ano permaneceram operando dessa forma, em 2000 lançaram formalmente a rede, inicialmente sob a forma de associação sem fins lucrativos, mas já com um regulamento formal.

Finalmente, em 2007 transformaram-se em atacado, nos mesmos moldes da rede $\mathrm{X}$. Na fase inicial e mesmo após a formalização da central foi relatada uma série de dificuldades com os próprios fornecedores, que: “... não acreditavam nesse sistema, preferindo vender mais caro loja a loja” (representante da rede Z), e com outros supermercadistas, que aumentaram as ações no sentido de enfrentar e se opor à central para proteger seu mercado.

Os resultados, em termos de aumento de vendas, foram se apresentando de maneira cada vez mais positiva. Com isso, foi se consolidando a união do 
grupo, a despeito de algumas saídas motivadas, segundo o representante da rede, por problemas mais particulares dos associados que saíram do que propriamente por um não alinhamento às diretrizes e normas estabelecidas. Por outro lado houve a entrada de novos associados, o que coincidentemente acabou resultando atualmente nos mesmos 13 participantes, número original de fundadores da central.

Contando atualmente com 13 supermercadistas e 14 lojas, a rede $\mathrm{Z}$ administra um total de 6.200 metros quadrados de área de vendas, operando com 35 check-outs e empregando 210 funcionários. Com esses dados pode-se dizer que a rede $Z$ está numa posição intermediária entre as redes $\mathrm{X}$ e $\mathrm{Y}$. $\mathrm{Z}$ difere de $X$ e se aproxima de $Y$ em termos de amplitude espacial de atuação. Enquanto a rede $X$ se espalha a partir de sua cidade sede para seis outras cidades em seu entorno, num raio de cerca de $90 \mathrm{~km}$, dos 13 integrantes da rede Z, apenas dois estão em duas cidades fora da cidade sede, uma concentração espacial semelhante à da rede $\mathrm{Y}$.

Com relação ao processo de seleção de parceiros, e a exemplo das centrais já relatadas, foram informados os mesmos processos de pesquisa de idoneidade e pontualidade junto a fornecedores, além da distância mínima de $2 \mathrm{~km}$ de qualquer associado, podendo essa última regra ser desconsiderada mediante a anuência do(s) supermercadista(s) atingido(s) pela maior proximidade do novo entrante. Houve também a formalização de parte do processo de seleção de novos parceiros, sob a forma de uma alienação de um bem, preferivelmente imóvel, de cada associado, no valor mínimo de $70 \%$ do valor da compra efetuada através da central.

Com relação aos encontros semanais entre os associados (espaços de deliberação, decisão e resolução de problemas), constatou-se que apesar de apenas recentemente ser lavrada ata, existe um maior nível de rigor com sanções monetárias para atrasos e faltas ( 1 real por minuto de atraso e 100 reais para a sétima falta). Diferentemente da rede $\mathrm{X}$, a rede $\mathrm{Z}$ ainda custeia sua estrutura, representada por nove funcionários, empilhadeira, um armazém de $900 \mathrm{~m}^{2}$, câmara fria, automóvel, ações de marketing (tablóides e propagandas diversas) através de mensalidade recolhida junto aos associados, proporcional ao valor adquirido através da central.

As relações de reciprocidade se revelaram da mesma forma que nas outras centrais, com a compensação de mercadorias sem controles formais (a não ser o controle interno de cada associado em termos de entrada e saída de mercadorias), baseadas apenas na confiança entre os participantes dessa transação. Sobre a intensidade das relações em termos de encontros em eventos sociais entre os associados foi relatado que existe uma amizade forte entre os associados, com participação de 70\% em encontros como jantares, churrascos etc.

\section{4. $O$ caso da rede $W$}

De acordo com o seu atual presidente (supermercadista $\mathrm{W} 1$ ), a rede $\mathrm{W}$ iniciou suas primeiras atividades conjuntas em 2000, por meio de uma ação desenvolvida por um consultor de empresas junto a 25 supermercadistas (40 lojas) de pequeno e médio porte da região (mesma cidade sede e região da rede $\mathrm{X}$ ), que foram convidados a iniciar uma experiência de associativismo: “... a rede começou como uma associação" (supermercadista W1).

Após aproximadamente seis meses de atividades e reuniões, o consultor, bem como vários associados se desligaram do trabalho: “... um desentrosamento dentro do grupo" (supermercadista W1), restando: “... aproximadamente 30\% do grupo inicial" (supermercadista W1). Os supermercadistas remanescentes resolveram por sua conta prosseguir com a associação, realizando compras conjuntas junto a fornecedores. Apesar de a principal motivação ter sido a obtenção de melhores condições de compra, surgiam outros compartilhamentos, prestações de serviços, trocas de informações etc. - “... você começa a ouvir pessoas que estão no mesmo ramo, trocar idéias..." (supermercadista W1).

O supermercadista W1 e mais dois outros supermercadistas com quem ele possui relação de amizade ingressaram na rede por convite em 2005. Na ocasião, a associação contava com sete associados, chegando-se assim a um número total de 10 associados naquele ano. Até 2008 operou como associação, com todas as limitações deste modelo já relatadas. Em meados de 2008 começaram as conversações para transformação da associação em atacado, convidando inclusive novos supermercadistas. Nesse processo foi visitada uma central mais antiga e desenvolvida, de porte maior e que adotava essa sistemática.

Da mesma forma que na rede $X$ foi necessária na criação do atacado uma adaptação preliminar composta pelo enquadramento pelo lucro real de cada associado, criação de elementos legais e operacionais, além da estrutura física. Esse processo durou cerca de um ano e meio e assim a central sob a forma de atacado passou a operar oficialmente em meados de 2010 (quatro meses antes dessa entrevista). Foi informada a existência de um sistema de controle sob a forma de garantia da parte de cada associado de um bem imóvel em nome da central, nos mesmos moldes da rede $X$. A partir desse momento também possibilitou-se a abertura para novos associados, que 
havia sido interrompida durante o processo de criação do atacado, e desde então foram admitidos mais três supermercadistas (quatro lojas), chegando-se a um total de 13 integrantes de uma ampla região geográfica que compreende 12 cidades. A rede W somava 19 lojas compreendendo 11 mil metros quadrados de área total de vendas. Operava com 650 funcionários e 111 check-outs. Apesar de seu porte ser então superior ao da rede $\mathrm{X}$, a rede $\mathrm{W}$, devido ao caráter recente de sua transição de associação para atacado, ainda não realizava alguns compartilhamentos como folhetos promocionais, por exemplo.

Os procedimentos de admissão seguiam dois caminhos. Um procedimento formal de atendimento às condições definidas no estatuto da rede, que além da garantia real e do enquadramento pelo lucro real, exige um enquadramento em termos de porte (número de lojas e faturamento mínimo) e distância mínima dos demais associados $(10 \mathrm{~km})$. Além disso, no caso de já existir um associado da rede na cidade do pretendente, exige-se a anuência desse associado. Por fim, existe a necessidade de se comprovar situação normal com fornecedores. Além desses procedimentos mais formalizados, e especialmente com relação aos últimos entrantes, houve visitas às instalações dos pretendentes por um grupo de associados da rede: “... fomos lá conhecer a estrutura deles e conhecer como eles operam" (supermercadista W1).

$\mathrm{Na}$ fase de atacado, relatou-se uma melhoria das condições de operação da central pois, como atacado, a rede $\mathrm{W}$ conseguiu acessar diretamente a indústria, não mais dependendo de outros atacados e lojas maiores para o seu abastecimento. Atualmente, além do armazém e dos escritórios, a rede $\mathrm{W}$ dispõe de um comprador e mais três funcionários administrativos. Quanto à movimentação de mercadorias, ainda é feita com veículos e pessoal próprio de cada associado.

0 mesmo esquema de reciprocidade em termos de compensação de mercadorias existente nas outras centrais também foi informado na rede W. Existe uma grande percepção de eficácia do entrevistado, que chegou a afirmar que se porventura saísse da atual central buscaria outra, e não apenas pela questão econômica, mas: “... hoje eu não me vejo fora de uma (central) pela troca de idéias, não somente pelo fato de comprar... você aprende muito ali” (supermercadista W1). Existem também laços de amizade e convivio social entre as famílias dos associados, com um churrasco mensal onde: “... também se fala de negócio mas levamos a família” (supermercadista W1). Também manifestou opinião de que a associação deveria ser mantida mesmo que não fosse mais possivel realizar compras conjuntas, apenas pela troca de informações, idéias e experiências.

\section{Análise comparativa}

Primeiramente, em termos de porte (vide Tabela 1), medido pelo tamanho médio das lojas (em termos de área de vendas/número de lojas; número de funcionários/número de lojas; número total de caixas/número de lojas de cada central), é possível classificar as centrais estudadas de duas formas. Se for considerado o universo de centrais de negócios filiadas à Apas e as informações da Tabela 2, as centrais aqui analisadas estão em um patamar inferior ao porte médio do conjunto de centrais filiadas à instituição. lsso em termos de área de vendas, número de funcionários e quantidade de caixas por loja, respectivamente $610 \mathrm{~m}^{2}$, 33 funcionários por loja e 5 caixas por loja. Pelos dados na Tabela 2, apenas a rede W estaria em torno dos números médios $\left(579 \mathrm{~m}^{2} /\right.$ loja, 34 func./loja e 6 caixas/loja), com todas as demais se situando em níveis inferiores. Em termos de cobertura geográfica existem algumas especificidades.

As centrais filiadas à Apas se espalham por outras cidades além da cidade de origem. Esse número em média varia entre 6 e 8 cidades, embora existam casos de abrangência bem maior, com centrais representadas em 16, 18 e até 26 cidades. As redes $\mathrm{Y}$ e $\mathrm{Z}$ fogem dessa regra, com uma amplitude geográfica bem menor, em 2 e 3 cidades, respectivamente. As razões não se situam na idade das centrais, pois a rede $Y$ tem sua fundação em 2006, sendo uma das mais recentes do estado, e a rede $\mathrm{Z}$ teve seu início bem antes, no ano de 1999. A quantidade de associados também não resolve a questão, pois enquanto a rede $\mathrm{Y}$ possui apenas 4 associados, a rede $\mathrm{Z}$ é formada

Tabela 2. Resumo dos dados levantados nos relatos.

\begin{tabular}{|c|c|c|c|c|c|c|c|c|c|c|}
\hline & Fundação & Associados & Lojas & $\mathrm{M}^{2}$ & Func. & Caixas & Cidades & $\mathrm{M}^{2} /$ Loja* & $\begin{array}{l}\text { Func./ } \\
\text { Loja }^{* *}\end{array}$ & $\begin{array}{l}\text { Caixa/ } \\
\text { Loja }^{* * * *}\end{array}$ \\
\hline Rede X & 2000 & 24 & 32 & 8.650 & 547 & 88 & 7 & 270 & 17 & 3 \\
\hline Rede $Y$ & 2006 & 4 & 8 & 3.150 & 125 & 28 & 2 & 394 & 16 & 4 \\
\hline Rede Z & 1999 & 13 & 14 & 6.200 & 210 & 35 & 3 & 443 & 15 & 3 \\
\hline Rede W & 2002 & 13 & 19 & 11.000 & 650 & 111 & 12 & 579 & 34 & 6 \\
\hline
\end{tabular}

${ }^{*} \mathrm{M}^{2}$ /Loja: área total dividida pelo total de lojas; ${ }^{* *}$ Func./Loja: número total de funcionários dividido pelo número total de lojas; ${ }^{* * * *}$ Caixa/Loja: número total de caixas dividido pelo total de lojas. Fonte: Comitê de Centrais de Negócios da Apas (ASSOCIAÇÃO..., 2009). 
por 13 supermercadistas. 0 porte da cidade sede, isoladamente, tampouco esclarece, pois enquanto a rede $\mathrm{Z}$ se encontra sediada em cidade de porte médio para grande, a rede $Y$ situa-se em cidade de porte bem menor.

Uma combinação do histórico da central e localização geográfica em termos de concentração populacional (e empresarial) indica uma possibilidade de resposta. A rede $Z$ encontra-se em região densamente povoada, com inúmeras cidades de porte semelhante e grande concorrência, razão provável da concentração da maioria de seus 13 associados na cidade sede, restando apenas um deles em cidade próxima (situação diferente da rede $\mathrm{W}$ que, com o mesmo número de associados, espalha suas atividades por 12 cidades). 0 caso da rede $Y$ tem duas explicações possiveis, primeiro o fato de ser relativamente mais nova em comparação com as demais, com menos de quatro anos de atividade, razão de seu menor porte e menor número de associados e, em segundo lugar, por a sua região ser menos povoada.

Em termos de estrutura de compartilhamento as redes, possuem uma série de semelhanças, conforme exposto no Quadro 1, indicando, em termos de estrutura operacional, uma conformação a demonstrar traços de processo isomórfico. Essas identidades puderam ser detectadas em pelo menos três pontos ligados à questão do isomorfismo.

Em primeiro lugar, um dos fatores geradores de mecanismos isomórficos destacados pela literatura, a centralização de fornecedores (quando parte dos fornecedores é comum), está presente na realidade das centrais estudadas, pois boa parte dos fornecedores dos supermercadistas é comum a todos.

No segundo ponto, ficou evidenciado ao longo das conversas com os supermercadistas das centrais pesquisadas que, quanto à forma de disseminação dos modelos de funcionamento das centrais, segue-se um dos meios explícitos relacionados por DiMaggio e Powell (1983). 0 meio em questão, as denominadas associações de comércio ou indústria, é aqui representado pela Apas (e suas centrais filiadas) como fornecedora de modelos e articuladora de ações conjuntas das centrais.
Quanto ao terceiro ponto, relacionado com as três formas de isomorfismo definidas por DiMaggio e Powell (1983) (coercitivo, normativo e mimético), o mais adequado para a realidade das centrais parece ser o mimético. Essa forma define-se como a adaptação de procedimentos e estruturas de uma organização que são percebidos e disseminados como sucessos por outra organização, com a finalidade de reduzir a incerteza. Em vários relatos foi mencionado o fato de, no início das redes, seus responsáveis terem buscado junto a outras centrais, ou à Apas, modelos de estatutos e procedimentos. Contudo, a mediação da Apas nesse processo, ao fornecer modelos de centrais e intermediar contatos entre os grupos intencionados em formar uma central e entre as já existentes, confere um aspecto também normativo ao processo isomórfico.

Nos relatos, a motivação inicial para a entrada e nascimento das redes converge para a questão da sobrevivência ante a concorrência. Em todas as entrevistas, a sobrevivência ante uma concorrência cada vez mais agressiva é alegada como a principal se não a única motivação. Assim, o caminho da compra conjunta torna-se uma possibilidade de solução para essa ameaça. Por outro lado, existe uma unanimidade em se afirmar que, depois de algum tempo de atividade da central, se junta ao ganho econômico proporcionado pela compra conjunta, um ganho não econômico gerado pela troca de informações, experiências e outros compartilhamentos. Esse ganho, segundo alguns relatos, se não supera o ganho econômico pela maior escala de compra, chega a igualar-se em termos de benefício percebido.

Com relação aos vínculos prévios, as redes $\mathrm{X}$ e $\mathrm{Z}$ relataram que os fundadores possuíam vínculos de amizade e parentesco. Mas nas redes $\mathrm{Y}$ e $\mathrm{W}$ esses vínculos não existiam ou, se existiam, eram muito fracos. Nesses últimos casos, em substituição aos vínculos prévios, entrou em cena um mecanismo catalisador representado pela ação de um ator externo crível, não só da Apas, mas de outros agentes (o Sebrae, no caso da rede $\mathrm{Y}$, e um consultor externo, no caso da rede $W$ ).

Constata-se também um ciclo de evolução que obedece basicamente a algumas fases. Uma fase inicial, onde as centrais nascem de maneira informal

Quadro 1. Estrutura das centrais.

\begin{tabular}{|l|l|}
\hline & \multicolumn{1}{c|}{ Estrutura } \\
\hline Rede $\mathrm{X}$ & Comprador, administrador, financeiro, faturista, carregadores \\
\hline Rede $\mathrm{Y}$ & Comprador, administrador, auxiliar administrativo \\
\hline Rede $\mathrm{Z}$ & Comprador (2), financeiro (2), conferente \\
\hline Rede $\mathrm{W}$ & Gerente de negócios, administrador, contador, financeiro, secretária \\
\hline
\end{tabular}

Fonte: Comitê de Centrais de Negócios da Apas (ASSOCIAÇÃO..., 2009). 
com algumas compras a título de teste em nome de um do grupo, logo após segue-se um momento de preparo da formalização caracterizado pela busca de modelos de funcionamento em outras redes ou na própria Apas. Após essa fase, segue-se a atuação sob forma de associação sem fins lucrativos. Nessa fase surgem alguns mecanismos mais formalizados, tais como estatutos e regulamentos.

Finalmente, com a consolidação do modelo, tem-se a criação de uma central atacadista. Nessa etapa, define-se normalmente a estrutura operacional da central, com a armazenagem e distribuição conjuntas, contratação de funcionários para gerir essa estrutura, definição de outras ações conjuntas etc. Essa etapa é considerada um salto de qualidade e escala para as centrais, pois dá condição de acesso direto à indústria, sem passar por atacadistas e lojas maiores, o que melhora sensivelmente as condições de compra. Também nessa etapa ainda se recorre a modelos de sucesso já existentes, com ou sem a intermediação da Apas.

Ao longo desse processo de evolução adquire importância crescente o mecanismo de seleção de novos associados. A forma de entrada passa de convites a supermercadistas com vínculos prévios com associados para um processo mais sistematizado, composto por uma série de critérios de admissibilidade dos interessados (pesquisa de idoneidade, distância geográfica, alienação de bens em garantia, equivalência de porte com os demais, visita às instalações do pretendente etc.).

Observa-se claramente, a existência de uma mescla entre formalidade e informalidade nesse procedimento. A pesquisa de idoneidade, da pontualidade e as visitas às instalações são informais, bem como boa parte das negociações. Por outro lado, a alienação do bem em garantia só se concretiza dentro de um rito formalizado. É importante salientar que o processo de seleção de parceiros não se encerra na entrada do pretendente na central pois, ao longo de sua trajetória dentro da central, o supermercadista deve alinhar-se aos propósitos comuns, normas e regras da central. Caso contrário, por uma série de processos formais e informais, este supermercadista se verá na impossibilidade de permanecer no grupo e, neste sentido, são vários os casos, em todas as centrais estudadas, de saídas de supermercadistas em razão desse não alinhamento.

Outros mecanismos de coordenação e controle que transitam entre o formal e o informal encontram-se de maneira disseminada nas quatro centrais. Por exemplo, decisões que se concretizam através do voto de cada associado nas reuniões semanais, com pesos iguais, o que reforça o caráter não hierárquico (sem centralidade) dessas centrais enquanto redes.
Com relação aos atributos para coesão relacional, especificamente a reciprocidade e confiança sob a forma da compensação mútua de mercadorias, essa coesão verificou-se de maneira pronunciada em todas as centrais, denotando-se um grau considerável de coesão. Outro atributo diz respeito à intensidade emocional, revelada nos relatos através da existência de relacionamentos de amizade, cultivados em eventos sociais regulares fora do ambiente de operações, nos quais os associados fortalecem seus vínculos e, com isso, aumentam a coesão do grupo.

\section{Conclusões}

São três as principais conclusões deste trabalho. Primeiramente, constataram-se, no desenvolvimento e na trajetória do grupo de redes estudado, indícios relevantes de um processo isomórfico de caráter predominantemente mimético mas, devido à presença da Apas, também com características normativas que se revelaram importantes para a compreensão da dinâmica do fenômeno de centrais de negócios supermercadistas. Em segundo lugar, no caso dos mecanismos de coordenação, especialmente a seleção de parceiros, nota-se uma importante combinação de formalidade e informalidade na coordenação, o que proporciona uma flexibilidade interessante em termos competitivos para os pequenos supermercados reunidos nesse tipo de arranjo, em face da competição com o modelo dos hipermercados. Em terceiro lugar, as relações entre os integrantes das redes estudadas se revelaram reciprocas, confiantes e, portanto, coesas, o que inclusive vem a favorecer a coordenação informal, que necessita da reciprocidade e da confiança para se desenvolver.

Por fim, o arranjo cooperativo em redes de pequenos supermercadistas denominado rede de compras ou centrais de negócios se apresenta como uma estrutura em rede passivel de ser classificada em uma nova categoria que combina características de diversas estruturas em rede. A formação em torno de centrais de negócios que coordenam suas transações e atividades com elementos de formalidade e informalidade passa, para as pequenas empresas do setor supermercadista, a ser considerada uma alternativa aos modelos tradicionais de atuação no setor.

\section{Referências}

ASSOCIAÇÃO PAULISTA DE SUPERMERCADOS. Comitê de Centrais de Negócios. Quadro: Lojas Associadas às Centrais de Negócios. São Paulo, 2009.

BOUÇAS, C. Varejo recupera vendas no fim do semestre. Valor econômico, São Paulo, 10 jul. 2009. Disponível 
em: <www.valoronline.com.br/Valor>. Acesso em: 06 ago. 2009.

CASAROTTO FILHO, N.; PIRES L. H. Redes de pequenas e médias empresas e desenvolvimento local: estratégias para a conquista da competitividade global com base na experiência italiana. 2. ed. São Paulo: Atlas, 2001. 176 p.

DiMAGGIO, P. J.; POWELL, W. W. The iron cage revisited: institutional isomorphism and collective rationality in organizational fields. American Sociological Review, v. 48, n. 2 , p. 147-160, 1983.

GHISI, F. A. Fatores críticos na sustentabilidade das centrais de negócios do setor supermercadista. 2005. Tese (Doutorado em administração)-Faculdade de Economia, Administração e Contabilidade. Universidade de São Paulo, São Paulo, 2005.

GRANDORI, A.; SODA, G. Inter-firm networks: antecedents, mechanisms and forms. Organization Studies, v. 16, n. 2, p. 183-214, 1995.

HALL, P. A.; TAYLOR, R. C. Political science and the three new institutionalism. Political Studies, n. 44, p. 936957, 1996.

HILÁRIO, W. Ranking 2008: setor recobra fôlego e cresce acima do PIB. Revista Super - Hiper, p. 36-118, 2008.

HILÁRIO, W.; LUKIANOCENKO, M. Ranking 2010. Revista Super - Hiper, v. 36, n. 407, p. 38-132, 2010.

LOPES, F. F. et al. Estratégias de rede de empresas: o associativismo no pequeno varejo alimentar. In:
CONGRESSO DA SOCIEDADE BRASILEIRA DE ECONOMIA RURAL - SOBER, 42., 2004, Cuiabá. Anais... Cuiabá, 2004.

MENARD, C. The economics of hybrids organizations. Journal of Institutional and Theoretical Economics, v. 160, n. 3, p. 345-376, 2004.

OLIVEIRA LIMA, D. et al. Redes de cooperação no varejo alimentar de vizinhança: percepção dos associados. Gestão \& Produção, v. 13, n. 2, p. 311-314, 2006. http:// dx.doi.org/10.1590/S0104-530X2006000200012

POWELL, W. W. Neither market nor hierarchy: network forms of organization. Research in Organization Behavior, v. 12, p. 295-336, 1990.

SACOMANO NETO, M.; TRUZZI, O. M. S. Governança e análise de redes. In: FUSCO, J. P. A. (Org.). Redes Produtivas e Cadeias de Fornecimento. São Paulo: Arte \& Ciência Editora, 2005. p. 141-273.

SATO, K. Vendas dos supermercados crescem 7,7\% em volume no primeiro bimestre. Jornal Valor Econômico, São Paulo, mar. 2010. Disponível em: <www.valoronline. com.br/Valor>. Acesso em: 30 mar. 2010.

WILDER, A. Mudanças no setor supermercadista e a formação de associações de pequenos supermercados. 2003. $208 \mathrm{f}$. Dissertação (Mestrado em Ciências - Economia Aplicada)-Escola Superior de Agricultura Luiz de Queiroz, Universidade de São Paulo, Piracicaba, 2003.

YIN, R. K. Estudo de Caso: planejamento e método. Porto Alegre: Bookman, 2005.

\section{Small-business central supermarkets in the state of São Paulo: the evolution of coordination and relations}

\section{Abstract}

This paper aims to demonstrate and analyze a group of small supermarket networks in the state of S. Paul, working through cooperative relationships in the form of core business. Using a qualitative research approach, this work is based on semi-structured interviews with representatives of four plants, using a script composed of items related to the central main motivations for entering the network, development phases, operational details and the coordination mechanisms and characteristics of the most relevant relations. In terms of coordination mechanisms, there is a coexistence of formal and informal mechanisms of coordination. The relations between members, in general, are shown to be cohesive. Finally, there is also a high perception of efficacy.

\section{Keywords}

Supermarkets. Networks. Coordination. Cohesion. Effectiveness. 